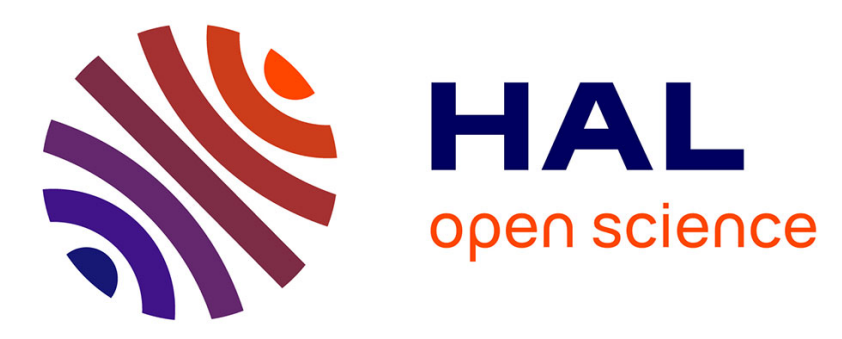

\title{
Shift-work and cardiovascular disease: a population-based 22-year follow-up study
}

Christer Hublin, Markku Partinen, Karoliina Koskenvuo, Karri Silventoinen, Markku Koskenvuo, Jaakko Kaprio

\section{- To cite this version:}

Christer Hublin, Markku Partinen, Karoliina Koskenvuo, Karri Silventoinen, Markku Koskenvuo, et al.. Shift-work and cardiovascular disease: a population-based 22-year follow-up study. European Journal of Epidemiology, 2010, 25 (5), pp.315-323. 10.1007/s10654-010-9439-3 . hal-00576254

\section{HAL Id: hal-00576254 \\ https://hal.science/hal-00576254}

Submitted on 14 Mar 2011

HAL is a multi-disciplinary open access archive for the deposit and dissemination of scientific research documents, whether they are published or not. The documents may come from teaching and research institutions in France or abroad, or from public or private research centers.
L'archive ouverte pluridisciplinaire HAL, est destinée au dépôt et à la diffusion de documents scientifiques de niveau recherche, publiés ou non, émanant des établissements d'enseignement et de recherche français ou étrangers, des laboratoires publics ou privés. 


\title{
Shift-work and cardiovascular disease: a population-based 22-year follow-up study
}

\author{
Christer Hublin · Markku Partinen • \\ Karoliina Koskenvuo $\cdot$ Karri Silventoinen • \\ Markku Koskenvuo · Jaakko Kaprio
}

Received: 31 August 2009/Accepted: 4 March 2010/Published online: 14 March 2010

(C) Springer Science+Business Media B.V. 2010

\begin{abstract}
Studies on the association between shift-work and cardiovascular disease (CVD), in particular coronary heart disease (CHD), have given conflicting results. In this prospective population-based study we assessed the association of shift-work with three endpoints: CHD mortality, disability retirement due to CVD, and incident hypertension. A cohort of 20,142 adults (the Finnish Twin Cohort) was followed from 1982 to 2003. Type of working time (daytime/nighttime/shift-work) was assessed by questionnaires in 1975 (response rate 89\%) and in 1981 (84\%). Causes of death, information on disability retirement and hypertension medication were obtained from nationwide official registers. Cox proportional hazard models were used to obtain hazard ratios (HR) for each endpoint by type of working time. Adjustments were made for 14 socio-demographic and lifestyle covariates. $76.9 \%$ were daytime workers and $9.5 \%$ shift-workers both
\end{abstract}

This work has been performed at the Department of Public Health, University of Helsinki, Helsinki, Finland. It has been partly presented at the 19th Congress of the European Sleep Research Society, Glasgow, UK, September 9-13, 2008.

\author{
C. Hublin $(\bowtie)$ \\ Brain@Work Research Center, Finnish Institute of Occupational \\ Health, Topeliuksenkatu 41 a A, 00250 Helsinki, Finland \\ e-mail: christer.hublin@ttl.fi \\ C. Hublin · M. Partinen \\ Department of Clinical Neurosciences, \\ University of Helsinki, Helsinki, Finland \\ M. Partinen \\ Vitalmed Sleep Clinic, Helsinki, Finland \\ K. Koskenvuo \\ The Social Insurance Institution of Finland, Helsinki, Finland
}

in 1975 and in 1981. During the follow-up, 857 deaths due to CHD, 721 disability retirements due to CVD, and 2,642 new cases of medicated hypertension were observed. However, HRs for shift-work were not significant (mortality HR men 1.09 and women 1.22; retirement 1.15 and 0.96 ; hypertension 1.15 and 0.98 , respectively). The results were essentially similar after full adjustments for all covariates. Within twin pairs, no association between shift work and outcome was observed. Our results do not support an association between shift-work and cardiovascular morbidity.

Keywords Shift-work - Coronary heart disease . Cardiovascular disease - Mortality - Disability retirement . Genetic effect

\section{Introduction}

Many work-related psychosocial factors, including work schedules, have been associated with the risk of cardiovascular disease (CVD) [1]. Despite evidence put forth for

\footnotetext{
K. Koskenvuo - K. Silventoinen · M. Koskenvuo · J. Kaprio Department of Public Health, University of Helsinki, Helsinki, Finland

K. Silventoinen

Population Research Unit, Department of Sociology, University of Helsinki, Helsinki, Finland

J. Kaprio

Department of Mental Health and Substance Abuse Services, National Institute for Health and Welfare, Helsinki, Finland

J. Kaprio

Institute for Molecular Medicine, Helsinki, Finland
} 
a modest excess risk for CVD among shift-workers compared with daytime workers [2] the heterogeneous nature of the studies (17 up to the year 2000) meant that no valid meta-analytic risk estimate could be computed [3]. In a very recent systematic review Frost et al. [4] concluded that the epidemiological evidence for a causal relation between shift-work and ischemic heart disease (or CHD) is limited. The review is based on 14 studies published before end of March 2008. Seven analyzed fatal events, six combined fatal and non-fatal events, and one study reported separately both types of events. Relative risks ranged from 0.6 to 1.4 in 12 papers while two papers reported relative risks around 2.0. Most studies based on fatal events showed no or weak associations but studies that combined fatal and non-fatal events showed modest positive associations. In a majority of studies negative or positive bias due to the quality of outcome or exposure information, or confounder control could not reasonably be ruled out [4]. Interestingly, there are only two studies $[5,6]$ assessing the risk in women.

Several hypotheses on the possible causal mechanisms between shift work and CVD or CHD have been presented. These include mismatch of circadian rhythm (affecting nutrition and causing stress related to sleep deprivation, leading to metabolic syndrome), social stress (due to isolation), unfavourable behavioral factors (increased smoking, sedentariness, poor diet), and lower socioeconomic status [2, 4].

There are few studies on the association between shiftwork and retirement. In a prospective Danish study with 15 years follow-up shift-work was not associated with disability pension in men, but the risk was increased in women even after adjustments for several possible confounders $\{$ hazard ratio $(\mathrm{HR})=1.34,95 \%$ confidence interval (CI) 1.02, 1.75 [7]\}. Several Japanese studies have shown an approximately 1.2 -fold risk in up to $30 \%$ increases both in systolic and diastolic blood pressure [8] and significantly increased risks (1.1-3.6 fold) [9-11] for hypertension have also been reported. Large prospective studies of hypertension risk in shift-workers are lacking in European and US populations.

In this study we assessed the association between type of working time (especially shift-work) in both genders and the risk of mortality due to $\mathrm{CHD}$, disability retirement due to CVD, and incident hypertension in a large, prospective, population-based cohort of Finnish adults with 22-year follow-up data and detailed information on potential confounding or effect-modifying factors. Differences in shift-work history among twin pairs discordant for cardiovascular outcome would support a causal hypothesis between this common exposure and these major public health problems.

\section{Methods}

The Finnish Twin Cohort

The Older Finnish Twin Cohort consists of all Finnish twin pairs of the same gender born before 1958 with both co-twins alive in 1975. These pairs were selected from the Central Population Registry of Finland in 1974 [12]. The first questionnaire was mailed in 1975 (response rate 89\%) and the second in 1981 (response rate 84\%). The questionnaires included questions on socio-demographics, health status, lifestyle and psychosocial factors including work patterns. The present analyses include those responding to the both questionnaires with information on working time, and resident in Finland in $1981(N=20,142 ; 51.2 \%$ women; mean age in 198140.2 years).

The study has been approved by the ethical committee of the Department of Public Health, University of Helsinki. Informed consent was obtained from all respondents.

\section{Questionnaire data}

Information on working time was asked (both in 1975 and 1981): "Is your present work or the work you last were doing: (1) mainly daytime work, (2) mainly nighttime work, (3) mainly shift- work, or (4) I have never been working". Physical work load was enquired about by asking (in 1981): "What type is/was your work: (1) mainly sitting, (2) standing and walking without other physical activity, (3) in addition to standing and walking also lifting and carrying, or (4) heavy physical work". Working pace was asked (in 1981): "How much can you influence your working pace: (1) I can relatively freely regulate it, (2). I can to some extent regulate it, (3) I can not regulate it, or (4) I am not working".

We assessed the following socio-demographic and lifestyle covariates (asked both in 1975 and 1981; see Table 1): married or cohabiting, social class (upper or lower white collar, skilled or unskilled workers, farmers, others), education (nine categories by years of school, high school equals to 12 years), smoking status (never, occasional, ex-, or current smoker), binge drinking [13, 14], grams of alcohol consumed daily (based on self-reported average quantities of beer, wine and spirits consumed) [15], self-report of hypertension (physician-made diagnosis or medication) [16], BMI (body mass index, $\mathrm{kg} / \mathrm{m}^{2}$ ), conditioning physical activity (sedentary, intermediate, vigorous physical activity) [17], life satisfaction [18], diurnal type [19], insufficient sleep [20], and sleep length and use of hypnotics and/or tranquillizers [21]. Life satisfaction correlates highly $(r=-0.63)$ with depression as assessed concurrently by the Beck Depression Inventory [22]. 


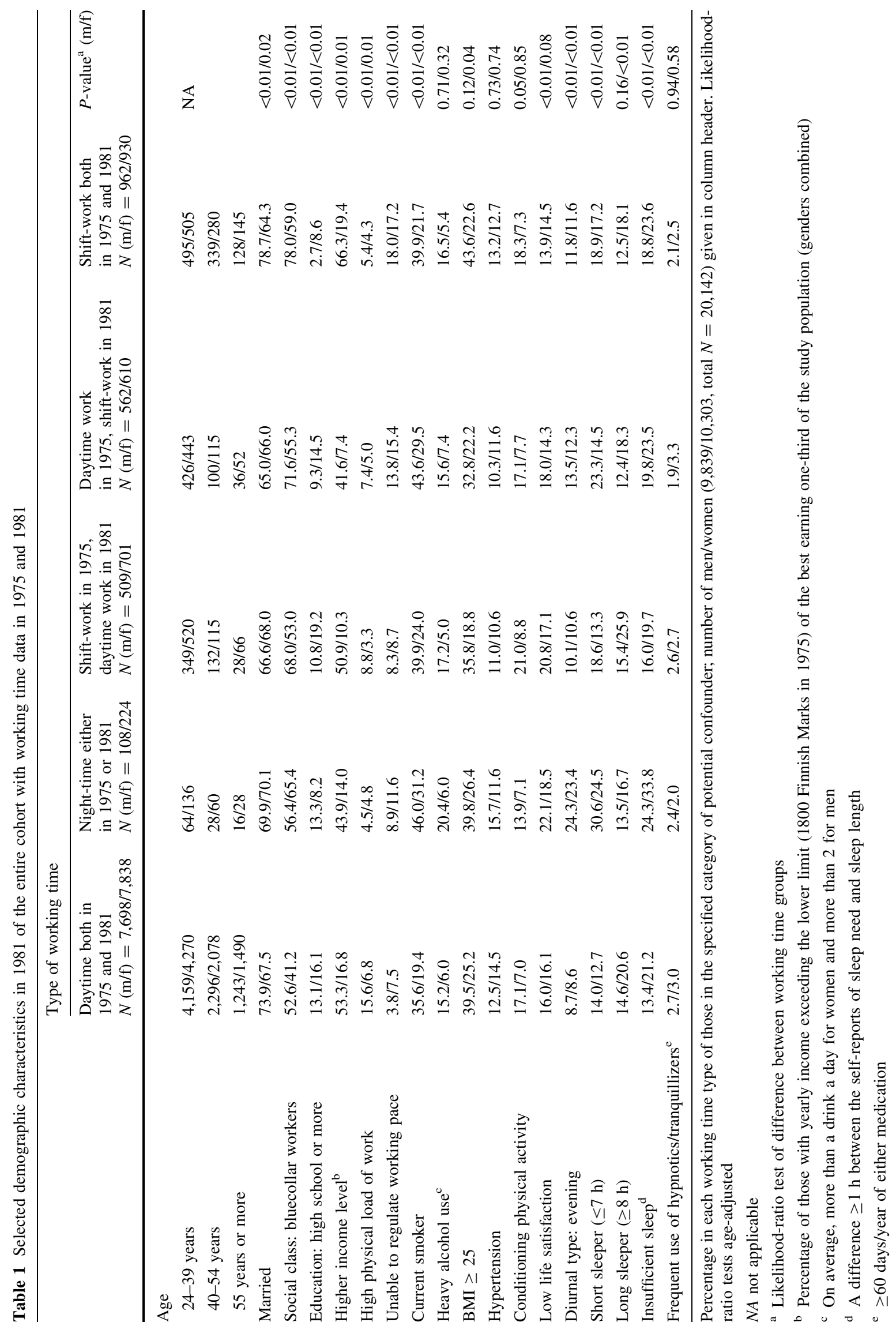


Additionally, we used information of working time (mainly daytime, nighttime, two-shift without night shift, two-shift with night shift, three-shift, never been working) from the 1990 questionnaire in a subgroup $(N=10,957$, $54.4 \%)$ to assess the stability of working time type.

\section{Follow-up data}

Vital status (alive in Finland on December 31, 2003, date of death or date of migration from Finland) was obtained from the Population Register Centre of Finland. The follow-up for mortality was from the exact date of response (date 1981 questionnaire returned) to December 31, 2003. Cause-of-death statistics of the underlying cause [due to CHD; ICD-10 codes I20-I25, and corresponding sections of ICD-8 and ICD-9 (codes 410-414)] were obtained from Statistics Finland. Information on disability retirement due to CVD [ICD-10 codes I00-I99, and corresponding sections of ICD-8 and ICD-9 (codes 390-459)] was obtained from the Finnish Social Insurance Institution (FSII) and the Finnish Centre for Pensions. Information of incident hypertension was obtained by record linkage of the Cohort data with the register of FSII on new cases of reimbursement of cost for medical treatment of hypertension. Reimbursement is granted after submission of a medical certificate by the treating physician, reviewed by the medical experts of the FSII. These registers cover all Finnish citizens. Our analyses are based on 402,266 person-years, and 857 deaths due to CHD, 721 disability retirements caused by CVD, and 2,642 new cases of hypertension during the follow-up.

Data analysis and statistical methods

The study population was grouped according to the type of working time (each subject belonging to one group) as follows (Table 1): group 1. daytime work both in 1975 and 1981, group 2. night-time work either in 1975 or 1981, group 3. shift-work in 1975 and daytime work in 1981, group 4. daytime work in 1975 and shift-work in 1981, and group 5. shift-work both in 1975 and 1981. These categories were used as our main interest was to compare the risks associated with constant shift work (group 5) to that with constant daytime work (group 1). Those ever working night-time formed a separate group as their number was small and they differed in many characteristics from the other groups (Table 1). Those not working or with missing data on working status were excluded $(N=1,096)$ from the analyses. Subjects on disability pension or retired prior to 1981 were excluded from the analyses of risk of disability retirement, and similarly those with baseline hypertension from the analysis of incident hypertension during the followup 1982-2003. Significance of differences in the prevalence of each covariate between the types of working time was assessed by computing likelihood-ratio tests from logistic regressions models including age with and without the shiftwork categories. As there are well known gender differences in CHD and CVD, the results are given separately for men and for women.

Cox proportional hazard models were used to obtain HR and their $95 \%$ CI for mortality due to CHD and disability retirement caused by CVD by type of working time. As the reference group we used those daytime working both in 1975 and 1981. The proportional-hazard assumptions were tested and confirmed using Schoenfeld residuals by examining that the log hazard-ratio function is constant over time for the shift-work variables, using the phtest option in Stata, which was used in all statistical analyses (version 9.2, Stata Corporation, College Station, Texas, USA). Also, plots of the $-\ln (-\ln$ (survival) vs. $\ln$ (age) were used to visually inspect the proportional hazards assumption. Because the study sample included twin pairs, standard errors and CIs were adjusted for possible within-pair correlations using robust estimators of variance [23].

Additionally, as the follow-up time is long, we also computed HRs for the mortality risk due to CHD up to 1990 to exclude the possibility that the risk might accumulate non-uniformly.

The risk of mortality and disability retirement was also calculated for the healthy-subgroup of the total study sample $(N=15,314)$. This includes the subjects without chronic diseases such as angina pectoris, cancer, myocardial infarction, stroke, diabetes mellitus or chronic obstructive pulmonary disease in 1981 based on the questionnaire and information from multiple medical registers $[24,25]$. The subjects with hypertension only were not excluded.

In the fully adjusted models, adjustments were made for the socio-demographic and lifestyle covariates (measured in 1981) that are potential confounders associated both with shift-work and risk of death (see above). The subjects with missing data on any of the covariates were excluded from the fully adjusted models.

Additionally, our twin data permitted us to compute polychoric correlations, which assess pairwise similarity of those shift-working both in 1975 and 1981 and those daytime working both in 1975 and 1981. The analysis was based on 916 male and 1,081 female monozygotic (MZ) pairs, and 1950 male and 2006 female dizygotic (DZ) pairs. Discordant pair analysis permits assessment of the possible causal relationship between shift-work and disease. This was performed in those pairs with one twin dying due to CHD during the follow-up (218 MZ and $568 \mathrm{DZ}$ pairs), to see if these twin-pairs differed in shift-work pattern while adjusting for latent familial factors shared by the twins, including partially (DZ pairs) or completely for genes (MZ). 


\section{Results}

Demographic characteristics are given in Table 1. Both in 1975 and 1981, 76.9\% were daytime working, 9.5\% shiftworking, and $1.7 \%$ had night-time work at either point. In 1975 , the most common job categories among men were metalworker, worker in process industry and working in transportation, and in women nursing, factory worker and assistant jobs in nursing/health care. In the subgroup with information of the working time type in 1990, of those with daytime work both in 1975 and 1981, 90.8\% were still daytime working, and of those shift-working both in 1975 and $1981,68.8 \%$ were still shift-working (of them $59.4 \%$ had night shifts).

When comparing the characteristics between different types of working time, there were significant differences among both genders in marital status, social class, education, work load and pace, smoking, diurnal type, short sleep, and insufficient sleep. Significant differences were found in physical activity and in life satisfaction among males, and in BMI and in long sleep among females. Between daytime working and shift-working, there were some notable differences. The proportions of low social class and low level of education were higher among shiftworkers. Among daytime workers there were less of those unable to regulate working pace and more of those with high physical work load. There were more short sleepers and evening-type persons among shift-workers, but these proportions were even higher among night-time workers. The proportion of those with higher income level was highest among shift-workers. Low life satisfaction was most prevalent among night-time workers and least prevalent among permanent shift-workers. The proportion of those frequently using hypnotics and/or tranquillizers was on the same level in all groups.

Initiating smoking between 1975 and 1981 (i.e. became current smokers) was significantly associated with working-time types only in women. Those women who had started shift-work after 1975 had a 1.5-fold greater risk $(\mathrm{HR}=1.49,95 \%$ CI 1.03, 2.16) of smoking initiation compared to consistent daytime workers. However, when former smokers were excluded from the analysis, the association attenuated and became non-significant, suggesting that initiating shift-work may be associated with a relapse to smoking among former smoking women.

The associations of type of working time with the risk of CHD mortality and with the risk of disability retirement due to CVD are shown in Table 2. The age-adjusted HRs for CHD mortality were highest but non-significant in night-time workers. No significant increase in the risk of CHD mortality was found among permanent shift-workers. In the full model the HRs were similar in the total population (with the exception of night-time working women), and in the healthy-subpopulation the risk was even lower. Expectedly an elevated risk of CHD mortality was found for current smokers, for those with hypertension and for those men with obesity $\left(\mathrm{BMI}>25 \mathrm{~kg} / \mathrm{m}^{2}\right)$. Thus, there was no significantly increased risk of $\mathrm{CHD}$ mortality among shift- and night workers as compared to permanent daytime workers. Also the estimates for mortality up to 1990 were essentially similar.

Age-adjusted risk of disability retirement due to CVD was significantly increased only in women starting shiftwork $(\mathrm{HR}=1.88 ; 95 \%$ CI 1.10, 3.20). In the full model, both in the total population and in the healthy-subpopulation, the HRs were generally decreased, with the statistically non-significant exceptions of healthy men stopping shift-work and healthy women starting shift-work. Low social class, hypertension and obesity (BMI $>25 \mathrm{~kg} / \mathrm{m}^{2}$ ) were associated with a higher risk of disability retirement due to CVD. In addition, current smoking and use of hypnotics/tranquillizers increased the risk of disability retirement in men (data not shown in Tables).

There were no significant increase in the risk of incident hypertension either in age-adjusted or in the fully adjusted model.

We carried out subgroup analyses. The CHD mortality risk by age-groups was analyzed separately for the both genders showing several increased HRs in a non-consistent pattern. No significantly increased risks were found except for middle-aged men who had started shift-work in 1981 $(\mathrm{HR}=2.09,95 \%$ CI 1.14-3.86). After full adjustment, the HR decreased and became non-significant.

In pairs discordant for $\mathrm{CHD}$, the odds ratios for shiftwork were non-significant, indicating no difference in shift-working patterns between twins in pairs where one consequently died from CHD.

\section{Discussion}

The present results do not support a direct association between shift-work and cardiovascular (CVD), especially coronary heart disease (CHD) risk, neither in men or women. There was no increase in the risk of mortality due to $\mathrm{CHD}$, disability retirement due to CVD, or incident hypertension among shift-workers compared to daytime workers during the 22-year follow-up. The results were similar also in the healthy subpopulation free of chronic disease. In twin pairs discordant for CHD, there was also no evidence for a shift-work effect.

Our study has several strengths: the large study sample (totally about 400,000 person-years) is representative of the general population with very high response rates, the number of cases was substantial (857 deaths and 721 retirements), the type of working time was measured twice, 


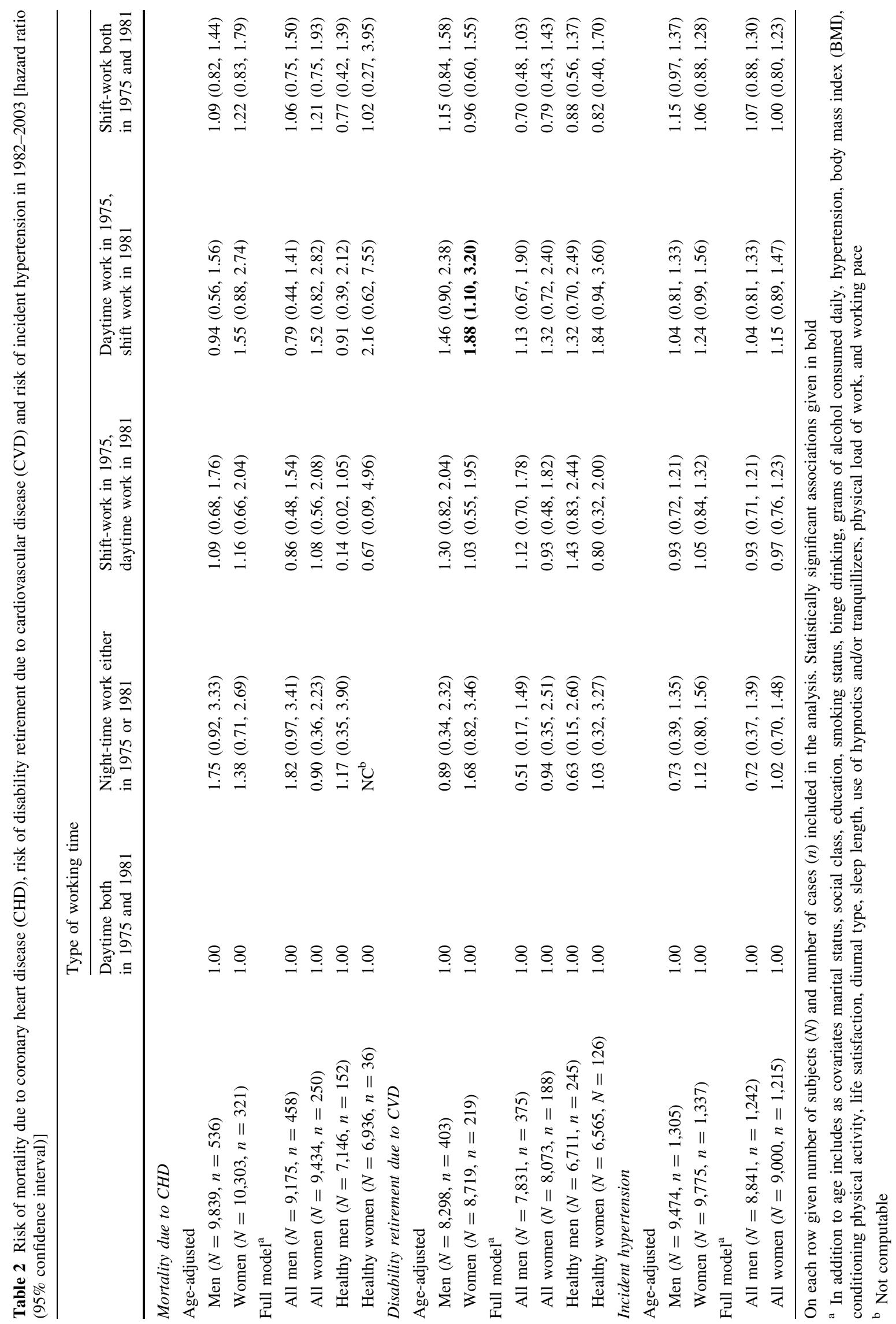


the information on potential confounding or effect-modifying factors was detailed, and the statistics on causes of deaths and retirement are comprehensive and reliable. Additionally, in our study information also on women was provided. There are no indications that rates of CHD and blood pressure levels would differ between singletons and twins [26, 27], and there is no reason why the association between shift work and outcome should be different in adult twin individuals and singletons doing similar work.

The recent systematic review [4] assessed 14 studies reporting on the risk of ischemic heart disease (or CHD) in relation to shift-work. Eight of these reported mortality data. In six studies the relative risks were $0.64-1.11$, based on 163-8,767 cases. An increased risk was found only in one study [5] with female American nurses (relative risk $1.19,95 \%$ CI $0.63-2.23, N=79,109$ ) and in another study [28] with male Japanese workers $(\mathrm{HR}=2.32,95 \%$ CI $1.37,3.95, N=17,649)$ but the number of cases were low (44 and 86, respectively). Two studies used employed males from general populations [28, 29] and five studies included male workers from industrial settings. The followup period was $>15$ years in four studies, and confounder control was limited in three studies [4]. In two studies $[5,28]$ the information on working hours was based on self-report. In seven studies the source of outcome has been based on death certificates. Methodologically, the present study is comparable, in some respects superior to the previously published mortality studies.

There is a striking difference in our results compared to those of Fujino et al. [28], despite methodological similarities: large population-based prospective study with long follow-up, self-report of working hours, adequate adjustment for possible confounders, and similar amount of person-years $(233,869$ vs. in the present study 193,061 male person-years). However, there may be variation in the CHD/CVD patterns between populations, explaining at least partly this difference. Also the socioeconomic status of shift-workers and exposure to other risk work-related and other factors may differ between countries: traditionally in Finland a typical male shift-worker is a well-earning paper-mill worker, whereas a typical female shift-worker works in low-income jobs in healthcare and social work sectors. Especially, there was a large difference in the number of CHD deaths (in Fujino et al. 86 CHD-deaths in the whole cohort and of them 18 in shift-workers, in our study 536 and 53, respectively). Serum levels of cholesterol and the prevalence and incidence of CHD are considerably lower in Japan compared to Western counterparts [30], which might affect the results.

Hypertension, dyslipidemia and smoking are the major acknowledged risk factors of CHD and CVD. However, it has been suggested that adjustment for these is not appropriate as they should not be considered confounders but rather steps in the causal chain $[2,31,32]$. Doing so would make it difficult to compare results in shift-work with other studies. There is evidence that smoking is more prevalent among shift-workers than daytime workers [2, 4, 33]. Our results suggest that initiating shift-work may be associated with a relapse to smoking among former smokers (especially in women), which is in accordance with the fact that smoking is generally initiated in adolescence before entering the work-life. As the relationships are complex, giving both adjusted and unadjusted results is advisable [34]. In the present study adjustment did not essentially change the results, not supporting a risk of over-adjustment. We found no association of shift-work with hypertension, suggesting it cannot be a step in the putative chain from shift-work to cardiovascular outcomes, while adjustment for smoking did not affect the estimates related to shift-work. Lipid measures were not available in our study.

Regarding other outcomes our results differed from the findings of previous studies. Overall, we found no significantly increased risk of disability pensions in women as reported in the Danish study [7], although age-adjusted risk was increased in women starting shift-work. We did not either found increased risk of hypertension as in Japanese studies [9-11].

Some limitations in our study need to be considered. First, the question in 1975 and 1981 on the type of working time did not specify the presence of night shifts. More detailed information of the details of the shift system would have been desirable as different systems may not be associated with similar effects, and a broad definition of shift-work could attenuate the association to CVD. Methodologically, a detailed assessment of the working schedules would be challenging in a study population derived from general population, as there is a multitude of different shift systems. However, studies assessing effects of shift work with and without night work, have not found clear indications for stronger effects among shift workers mainly working during nights compared to those who did not work at night [4]. In Finland in 1984, 44\% of men and 35\% of women shiftworking were working in three shifts [35]. It is also unclear what relation is between the risk and the amount of years of shift-work [4]. In the present study shift-working seemed to be long-lasting as in a subgroup with information of working time in 1990 about $2 / 3$ were still working in shifts of those who were shift-working both in 1975 and 1981. Secondly, it may be argued that disability retirement due to CVD is not a reliable outcome as it is possible that at least a part of the workers with CVD change to daytime work rather than become disability retired, which might dilute our result. However, this is not supported by a Finnish study among nurses showing that the possibility of employees with cardiovascular problems leaving their workplace was independent of work schedule [36]. Third, we did not study a 
cohort of shift workers but a sample of general population with subjects with different types of working hours. Therefore, this study is free from risks which may be associated with a single line of business, and our results may be applicable to the population in general. However, both approaches have their relevant aspects.

In conclusion, our results do not support an association between shift-work and increased risk of CVD, CHD, or hypertension either in men or in women. More prospective studies with large representative populations, long followups, reliable measure of exposure to shift-work, and adequate control of confounders are needed.

Acknowledgments Supported by the Academy of Finland Center of Excellence in Complex Disease Genetics and the Social Insurance Institution of Finland.

\section{References}

1. Knutsson A. Health disorders of shift workers. Occup Med. 2003;53:103-8.

2. Bøggild H, Knutsson A. Shift work, risk factors and cardiovascular disease. Scand J Work Environ Health. 1999;25:85-99.

3. Bøggild H, Knutsson A. Shift work and heart disease: meta analysis of the epidemiological literature. In: Hornberger S, Knauth P, Costa G, Folkard S, editors. Shift work in the 21st century: challenges for research and practice. Frankfurt am Main: Peter Lang; 2000. p. 189-94.

4. Frost P, Kolstad HA, Bonde JP. Shift work and the risk of ischemic heart disease-a systematic review of the epidemiologic evidence. Scand J Work Environ Health. 2009;35:163-79.

5. Kawachi I, Colditz GA, Stampfer MJ, Willett WC, Manson JE, Speizer FE, et al. Prospective study of shift work and risk of coronary heart disease in women. Circulation. 1995;92:3178-82.

6. Knutsson A, Hallquist J, Reuterwall C, Theorell T, Akerstedt T. Shiftwork and myocardial infarction: a case-control study. Occup Environ Med. 1999;56:46-50.

7. Tüchsen F, Christensen KB, Lund T, Feveile H. A 15-year prospective study of shift work and disability pension. Occup Environ Med. 2008;65:283-5.

8. Suwazono Y, Dochi M, Sakata K, Okubo Y, Oishi M, Tanaka K, et al. Shift work is a risk factor for increased blood pressure in Japanese men: a 14-year historical cohort study. Hypertension. 2008;52:581-6.

9. Morikawa Y, Nakagawa H, Miura K, Ishizaki M, Tabata M, Nishijo M, et al. Relationship between shift work and onset of hypertension in a cohort of manual workers. Scand J Work Environ Health. 1999;25:100-4.

10. Sakata K, Suwazono Y, Harada H, Okubo Y, Kobayashi E, Nogawa K. The relationship between shift work and the onset of hypertension in male Japanese workers. J Occup Environ Med. 2003;45:1002-6.

11. Oishi M, Suwazono Y, Sakata K, Okubo Y, Harada H, Kobayashi $\mathrm{E}$, et al. A longitudinal study on the relationship between shift work and the progression of hypertension in male Japanese workers. J Hypertens. 2005;23:2173-8.

12. Kaprio J, Koskenvuo M. Genetic and environmental factors in complex diseases: the Older Finnish Twin Cohort. Twin Research. 2002;5:358-65.
13. Kaprio J, Koskenvuo M, Langinvainio H, Romanov K, Sarna S, Rose RJ. Genetic influences on use and abuse of alcohol: a study of 5638 adult Finnish twin brothers. Alcohol Clin Exp Res. 1987;11:349-56.

14. Järvenpää T, Rinne JO, Koskenvuo M, Räihä I, Kaprio J. Binge drinking in midlife and dementia risk. Epidemiology. 2005;16: 766-71.

15. Romanov K, Rose RJ, Kaprio J, Koskenvuo M, Langinvainio H, Sarna S. Self-reported alcohol use: a longitudinal study of 12, 994 adults. Alcohol Alcohol. 1987;S1:619-23.

16. Hernelahti M, Kujala U, Kaprio J. Stability and change of volume and intensity of physical activity as predictors of hypertension. Scand J Public Health. 2004;32:303-9.

17. Kujala UM, Kaprio J, Sarna S, Koskenvuo M. Relationship of leisure-time physical activity and mortality. JAMA. 1998;279: $440-4$.

18. Koivumaa-Honkanen H, Honkanen R, Antikainen R, et al. Selfreported life satisfaction and recovery from depression in a 1-year prospective study. Acta Psychiatr Scand. 2001;103:38-44.

19. Koskenvuo M, Hublin C, Partinen M, Kaprio J. Heritability of diurnal types: a nationwide study of 9212 adult twin pairs. J Sleep Res. 2007;16:156-62.

20. Hublin C, Kaprio J, Partinen M, Koskenvuo M. Insufficient sleep: a population based study in adults. Sleep. 2001;24:392-400.

21. Hublin C, Partinen M, Koskenvuo M, Kaprio J. Sleep and mortality: a population-based 22-year follow-up study. Sleep. 2007; 30:1245-53.

22. Koivumaa-Honkanen $\mathrm{H}$, Kaprio J, Honkanen R, Viinamäki $\mathrm{H}$, Koskenvuo M. Life satisfaction and depression in a 15 -year follow-up of healthy adults. Soc Psychiatr Psychiatr Epidemiol. 2004;39:994-9.

23. Williams RL. A note on robust variance estimation for clustercorrelated data. Biometrics. 2000;56:645-6.

24. Kujala UM, Kaprio J, Koskenvuo M. Modifiable risk factors as predictors of all-cause mortality: the roles of genetics and childhood environment. Am J Epidemiol. 2002;156:985-93.

25. Sørensen TI, Rissanen A, Korkeila M, Kaprio J. Intention to lose weight, weight changes, and 18 -y mortality in overweight individuals without co-morbidities. PLoS Med. 2005;2:e171.

26. Christensen K, Wienke A, Skytthe A, Holm NV, Vaupel JW, Yashin AI. Cardiovascular mortality in twins and the fetal origins hypothesis. Twin Res. 2001;4:344-9.

27. de Geus EJ, Posthuma D, Ijzerman RG, Boomsma DI. Comparing blood pressure of twins and their singleton siblings: being a twin does not affect adult blood pressure. Twin Res. 2001;4:385-91.

28. Fujino $\mathrm{Y}$, Iso H, Tamakoshi A, Inaba $\mathrm{Y}$, Koizumi A, Kubo T, et al. Japanese Collaborative Cohort Study Group. A prospective cohort study of shift work and risk of ischemic heart disease in Japanese male workers. Am J Epidemiol. 2006;164:128-35.

29. Virtanen SV, Notkola V. Socioeconomic inequalities in cardiovascular mortality and the role of work: a register study of Finnish men. Int J Epidemiol. 2002;31:614-21.

30. Ueshima H. Explanation for the Japanese paradox: prevention of increase in coronary heart disease and reduction in stroke. $\mathrm{J}$ Atheroscler Thromb. 2007;14:278-86.

31. Tüchsen F, Hannerz H, Burr H. A 12 year prospective study of circulatory disease among Danish shift workers. Occup Environ Med. 2006;63:451-5.

32. Knutsson A. Shift work and ischaemic heart disease. Occup Environ Med. 2008;65:152.

33. van Amelsvoort LG, Jansen NW, Kant I. Smoking among shift workers: more than a confounding factor. Chronobiol Int. 2006; 23:1105-13. 
34. Knutsson A. Methodological aspects of shift-work research. Chronobiol Int. 2004;21:1037-47.

35. Lehto AM, Sutela H. Threats and Opportunities. Findings of Finnish Quality of Work life Surveys 1977-2003. Helsinki: Statistics Finland; 2005
36. Kivimäki M, Virtanen M, Elovainio M, Väänänen A, Keltikangas-Järvinen L, Vahtera J. Prevalent cardiovascular disease, risk factors and selection out of shift work. Scand J Work Environ Health. 2006;32:204-8. 